OPEN ACCESS

Edited by:

Yimin Zhu,

Zhejiang University, China

Reviewed by:

Hang Ying Lou,

Zhejiang University, China

Zhiqi Liao,

Huazhong University of Science and

Technology, China

*Correspondence:

Yan Meng

ctmengyan@njmu.edu.cn

Jiayin Liu

jyliu_nj@126.com

Specialty section:

This article was submitted to

Reproduction,

a section of the journal

Frontiers in Endocrinology

Received: 02 December 2021

Accepted: 11 January 2022

Published: 07 February 2022

Citation:

Xia X, Chen L, Wang J, Yu X, Gao L, Zhang Y, Diao F, Cui Y, Liu J and Meng Y (2022) Evaluation of Bone

Mineral Density in Children

Conceived via Assisted

Reproductive Technology.

Front. Endocrinol. 13:827978. doi: 10.3389/fendo.2022.827978

\section{Evaluation of Bone Mineral Density in Children Conceived via Assisted Reproductive Technology}

\author{
Xinru Xia ${ }^{1}$, Lingling Chen ${ }^{1}$, Jing Wang ${ }^{1}$, Xiang $\mathrm{Yu}^{2}{ }^{2}$, Li Gao ${ }^{1}$, Yuan Zhang ${ }^{1}$, Feiyang Diao ${ }^{1}$, \\ Yugui Cui ${ }^{1}$, Jiayin Liu $^{1 *}$ and Yan Meng ${ }^{1 *}$ \\ 1 State Key Laboratory of Reproductive Medicine, Center for Clinical Reproductive Medicine, First Affiliated Hospital, \\ Nanjing Medical University, Nanjing, China, ${ }^{2}$ Department of Pediatrics, First Affiliated Hospital, Nanjing Medical University, \\ Nanjing, China
}

Objectives: To investigate bone mineral density (BMD) differences between assisted reproductive technology (ART)-conceived children and naturally conceived (NC) children.

Study Design: This retrospective cohort study included ART-conceived children and controls aged 1 to 12 years assessed with a follow-up protocol. Maternal and paternal background, birth condition, and growth and development indicators were analyzed.

Results: The ART and NC groups exhibited differences in maternal and paternal childbearing age; maternal weight; maternal body mass index (BMI); maternal alcohol consumption; paternal smoking; delivery method; and serum zinc, iron, and lead levels. Multifactor analysis adjusted for relevant factors showed that paternal childbearing age and group significantly affected the BMD $Z$ score. In the subgroup analysis, in vitro fertilization (IVF) ( $p=0.026$ ) or intracytoplasmic sperm injection (ICSI) ( $p=0.008)$ had a positive impact on the BMD $Z$ score. Male infertility only $(p=0.010)$ or male infertility combined with polycystic ovary syndrome (PCOS) $(p=0.026)$ may affect the BMD Z score. In the embryo transfer cycle subgroup analysis, compared with natural conception, both stimulation cycle fresh embryo transfer $(p=0.019)$ and natural cycle frozen embryo transfer $(p=0.006)$ had a positive effect on the BMD Z score.

Conclusions: The BMD levels of the ART and control groups were generally in the normal range. Paternal childbearing age and the use of ART independently affected the BMD $Z$ score of the offspring.

Keywords: bone mineral density, bone development, infertility, assisted reproductive technology, childbearing age

\section{INTRODUCTION}

Infertility has become an increasingly common health problem, affecting approximately 48.5 million couples worldwide (1). Due to its high prevalence, it is regarded as a social disease by the World Health Organization. There are many reasons for infertility, and they vary from person to person. Assisted reproductive technology (ART) is one of the three main treatment strategies used 
for infertility. In recent decades, there has been great progress in ART, especially in the fields of fertility preservation, preimplantation aneuploidy screening, uterine transplantation and mitochondrial replacement technology to prevent serious diseases, and previously incurable cases have been successfully treated (2-5). However, the risks of multiple birth, premature birth, very premature birth, low birth weight, very low birth weight, small for gestational age, congenital malformations, and birth defects are significantly increased in ART offspring (6-10). Bone density is the most sensitive early warning factor for osteoporosis. Osteoporosis is a serious disease, and there is inconsistent evidence regarding whether there is a difference in bone mineral density (BMD) in the offspring conceived by ART.

A study in 2015 showed that the speed of sound (SOS) level measured within 96 hours in ART preterm infants was lower than that measured in the naturally conceived (NC) group (11). However, another population-based study reported that there was no statistically significant difference in BMD between offspring aged 4 and 10 years who were born via in vitro fertilization (IVF) and fresh embryo transfer and those born via natural conception (12).

$\mathrm{BMD}$ is defined as the mass of bone mineral per unit volume. BMD is an indicator not only of the status of bone salt deposition but also of the status of bone development in children and adolescents (13). Childhood and adolescence are critical periods for bone development. Osteoporosis that occurs later in life is thought to have originated in childhood or adolescence (14). Thus, prevention and treatment of bone mineral deficiency in children is a key step to reducing the occurrence of osteoporosis in adulthood. The study of BMD in childhood has important healthcare significance.

BMD is affected by many factors, including genetic factors, birth state $(15-17)$, age $(18)$, sex $(18)$, height $(18,19)$, nutrition (vitamin D and calcium intake) (19-21), pubertal status (19), life behavior (sun exposure, duration of breastfeeding or dietary pattern $)(19,22,23)$, physical activity $(19,21)$, body composition (overall body mass, lean body mass or body fat mass) (24-26) and diseases (27-34).

Additionally, the health of offspring born after ART has been a focus of public attention. Whether ART itself or parental infertility affects the BMD of the offspring has not yet been reported.

Therefore, the purpose of this study was to determine whether the BMD of ART offspring is affected by infertility or ART itself and to explore the possible mechanism by which parental fertility and ART influence BMD to promote the bone health of ARTconceived children.

\section{MATERIALS AND METHODS}

\section{Subjects}

The children who were recruited were conceived via ART in our center (ART group) or were NC (NC group) and came to our hospital for a physical examination in the Child Health Department from 2012 to 2015. The ART-conceived offspring included live-born infants from 2001 to 2014 in the Clinic Center of Reproductive Medicine of Jiangsu Province Hospital. The two groups were matched according to their age in months. Local institutional (First Affiliated Hospital of Nanjing Medical University) ethical approval (2012-SR-048) was obtained prior to data collection.

The inclusion criteria for the ART group were as follows: willingness to participate voluntarily and cooperatively, prepubertal status, singleton birth, full-term birth, in vitro fertilization and embryo transfer (IVF-ET) or ICSI as the ART method, infertility factors that included polycystic ovary syndrome (PCOS) and/or male factors (oligoasthenospermia, spermatogenic dysfunction or obstructive azoospermia), and embryo transfer cycle that was carried out via a fresh embryo being transferred in a stimulated cycle or a frozen embryo being transferred in a natural cycle.

The inclusion criteria for the NC group were as follows: willingness to participate voluntarily and cooperatively, prepubertal status, singleton birth, full-term birth, and natural conception.

The exclusion criteria for the ART group were as follows: illness or use of drugs, trauma or fracture, high-intensity sports training, family history of metabolic diseases, use of glucocorticoids by the mother during pregnancy, and donated sperm or eggs.

The exclusion criteria for the NC group were as follows: illness or use of drugs, trauma or fracture, high-intensity sports training, family history of metabolic diseases, and use of glucocorticoids by the mother during pregnancy.

In total, 84 individuals were included in the ART group, and 123 individuals were included in the NC group. Informed consent was obtained from a guardian of each participant included in this study.

\section{Follow-Up Process}

Two weeks before follow-up, the subjects were notified by telephone of the time, place and contact person for the followup assessment.

The day before the follow-up assessment, the participants were called to confirm whether they were free to participate. The pregnancy information of the ART group was retrieved and printed from the Center of Clinical Reproductive Medicine system.

On the day of the follow-up, the specific follow-up procedure was explained, and an informed consent form was signed by the patient. The Pediatrics department conducted general physical examinations (height and weight), trace element analyses, and bone density tests. Parents filled out the questionnaire. After all the items were completed, the information was checked, and it was confirmed that there were no omissions; then, the data were entered into the computer.

\section{Ultrasound Scans}

Using an Omnisense 7000P ultrasonic bone densitometer (Sunlight Medical Co., Ltd., Tel Aviv, Israel), after calibration by professional operators each day, the ultrasonic propagation velocity value (SOS) in the middle of the left tibia was measured by a standard method. The $\mathrm{Z}$ score of the SOS value of Asian children of the same age and sex was used as the standard. 


\section{Measurement of Height and Weight}

Height and weight were measured at the Department of Children's Health Care by skilled personnel. The accuracy was within $0.1 \mathrm{~cm}$ and $0.1 \mathrm{~kg}$, respectively. Body mass index $(\mathrm{BMI})=$ weight $(\mathrm{kg}) /$ height $(\mathrm{m})^{2}$.

\section{Determination of Trace Elements}

Peripheral blood was taken from the child's ring finger. The levels of zinc $(\mathrm{Zn})$, copper $(\mathrm{Cu})$, iron $(\mathrm{Fe})$, calcium $(\mathrm{Ca})$, magnesium $(\mathrm{Mg})$ and lead $(\mathrm{Pb})$ in peripheral blood were analyzed by an AA7000M atomic absorption spectrometer (East \& West Analytical Instruments Co., Ltd., Beijing, China). The following normal ranges for different elements were applied: $\mathrm{Zn}(\mathrm{mg} / \mathrm{L}): 5-11.94$; $\mathrm{Cu}$ (mg/L): 0.76-2.5; Fe (mg/L): 418.48660.8; Ca (mg/L): 84-62.86; Mg (mg/L): 28.3-50.4; and Pb ( $\mu \mathrm{g} /$ L): $0-100$.

\section{Statistical Analysis}

Data were analyzed using IBM SPSS 17.0 for Windows (SPSS, Inc., Chicago, IL, USA). In the single factor analysis, normally distributed continuous data are presented as the mean \pm standard deviation (SD), and nonnormally distributed continuous data are presented as the median (interquartile range). Categorical data are presented as the frequency (\%). Normally distributed continuous data were compared using an independent $t$ test, and nonnormally distributed continuous data were compared using the Mann-Whitney $U$ test. Unordered categorical data were compared using the chi-squared test, and ordered categorical data were compared using the rank-sum test. In the multifactor analysis, multiple linear regression analysis was used. Statistical significance was defined as $\mathrm{p}<0.05$.

\section{RESULTS}

\section{Single Factor Analysis of Bone Mineral Density-Related Factors}

We evaluated whether there was a difference in indicators between the two groups (Table 1) and found that there was no significant difference in maternal height, smoking, paternal height, paternal weight, paternal BMI, alcohol consumption, full-term birth, amniotic fluid characteristics, birth length, birth weight, sex, age, height, weight, $\mathrm{BMI}, \mathrm{Cu}, \mathrm{Ca}$, or $\mathrm{Mg}$ between the ART and NC groups. On the one hand, there was a significant reduction in $\mathrm{Zn}(\mathrm{p}=0.009)$ and $\mathrm{Fe}(\mathrm{p}=0.001)$ in the ART group compared with the NC group; on the other hand, maternal childbearing age $(\mathrm{p}=0.002)$, maternal weight $(\mathrm{p}=0.031)$, maternal BMI $(p=0.021)$, paternal childbearing age $(p=0.001)$, cesarean section rate $(p=0.000)$ and $\mathrm{Pb}$ level $(\mathrm{p}=0.000)$ were significantly higher in the ART group than in the NC group. There was also a significant difference in maternal alcohol consumption $(\mathrm{p}=0.016)$ and paternal smoking $(\mathrm{p}=0.000)$ prevalence between the two groups.

The medians of the $\mathrm{Z}$ scores of the two groups were within the normal range, indicating that the total bone density level was not significantly abnormal in the ART or NC children.
TABLE 1 | Single-factor analysis of bone mineral density-related factors.

\begin{tabular}{|c|c|c|c|}
\hline & ART group (84) & NC group (123) & $P$ value \\
\hline Maternal childbearing age (years) & $30(27,32)$ & $28(26,30)$ & $0.002^{\star *}$ \\
\hline Maternal height $(\mathrm{cm})$ & $\begin{array}{c}160.5(158.0 \\
165.0)\end{array}$ & $\begin{array}{c}160.0(158.0 \\
165.0)\end{array}$ & 0.694 \\
\hline Maternal weight (kg) & $59.0(53.0,65.8)$ & $55.0(51.0,61.7)$ & $0.031^{\star}$ \\
\hline Maternal BMI $\left(\mathrm{kg} / \mathrm{m}^{2}\right)$ & $22.5(20.4,25.1)$ & $21.3(20.0,23.4)$ & $0.021^{*}$ \\
\hline Maternal smoking: Never & $77(91.7)$ & $108(87.8)$ & 0.826 \\
\hline Ever & 0 & $2(1.6)$ & \\
\hline Occasionally & $3(3.6)$ & $2(1.6)$ & \\
\hline Still & 0 & $1(0.8)$ & \\
\hline Missing & $4(4.8)$ & $10(8.1)$ & \\
\hline Maternal alcohol use: Never & $68(81.0)$ & $78(63.4)$ & $0.016^{*}$ \\
\hline Ever & $3(3.6)$ & 0 & \\
\hline Occasionally & $11(13.1)$ & $35(28.5)$ & \\
\hline Still & 0 & 0 & \\
\hline Missing & $2(2.4)$ & $10(8.1)$ & \\
\hline $\begin{array}{l}\text { Paternal childbearing age } \\
\text { (years) }\end{array}$ & $32.5(30,35)$ & $30(28,33)$ & $0.001^{\star \star}$ \\
\hline Paternal height (cm) & $\begin{array}{l}173.0(170.0 \\
176.0)\end{array}$ & $\begin{array}{c}173.0(170.0 \\
176.0)\end{array}$ & 0.702 \\
\hline Paternal weight (kg) & $70.0(65.0,76.0)$ & $75.0(66.5,80.0)$ & 0.181 \\
\hline Paternal BMI $\left(\mathrm{kg} / \mathrm{m}^{2}\right)$ & $24.3 \pm 2.99$ & $24.8 \pm 3.44$ & 0.309 \\
\hline Paternal smoking: Never & $20(23.8)$ & $31(25.2)$ & $0.000^{\star \star \star}$ \\
\hline Ever & $7(8.3)$ & $7(5.7)$ & \\
\hline Occasionally & $10(11.9)$ & $20(16.3)$ & \\
\hline Still & $41(48.8)$ & $52(42.3)$ & \\
\hline Missing & $6(7.1)$ & $13(10.6)$ & \\
\hline Paternal alcohol use: Never & $18(21.4)$ & $26(21.1)$ & 0.973 \\
\hline Ever & $5(6.0)$ & $5(4.1)$ & \\
\hline Occasionally & $47(56.0)$ & $60(48.8)$ & \\
\hline Still & $9(10.7)$ & $18(14.6)$ & \\
\hline Missing & $5(6.0)$ & $14(11.4)$ & \\
\hline $\begin{array}{l}\text { Gestational age: Premature } \\
\text { birth }\end{array}$ & $8(9.5)$ & $6(4.9)$ & 0.421 \\
\hline Full-term birth & $73(86.9)$ & $86(69.9)$ & \\
\hline Missing & $3(3.6)$ & $31(25.2)$ & \\
\hline $\begin{array}{l}\text { Delivery mode: Spontaneous } \\
\text { delivery }\end{array}$ & $17(23.9)$ & $54(76.1)$ & $0.000^{\star \star \star}$ \\
\hline Caesarean section & $63(54.3)$ & $53(45.7)$ & \\
\hline Missing & $4(20.0)$ & $16(80.0)$ & \\
\hline $\begin{array}{l}\text { Amniotic fluid characteristic: } \\
\text { Clean }\end{array}$ & $74(88.1)$ & $92(74.8)$ & 0.096 \\
\hline $1^{\circ}$ & 0 & $5(4.1)$ & \\
\hline$\|^{\circ}$ & $1(1.2)$ & $3(2.4)$ & \\
\hline\|\|$^{\circ}$ & $1(1.2)$ & $1(0.8)$ & \\
\hline Missing & $8(9.5)$ & $22(17.9)$ & \\
\hline Birth height (cm) & $50.0(50.0,51.0)$ & $50.0(50.0,51.0)$ & 0.543 \\
\hline Birth weight (kg) & $3.5(3.0,3.8)$ & $3.5(3.2,3.8)$ & 0.738 \\
\hline Sex: Male & $46(43)$ & $61(57)$ & 0.482 \\
\hline Female & $38(38)$ & $62(62)$ & \\
\hline Age (months) & $35(21.25,46)$ & $35(20,60.25)$ & 0.381 \\
\hline Height (cm) & $96.3 \pm 13.85$ & $98.6 \pm 18.13$ & 0.298 \\
\hline Weight (kg) & $14.8(12.4,17.9)$ & $14.9(11.7,19.0)$ & 0.618 \\
\hline BMI $\left(\mathrm{kg} / \mathrm{m}^{2}\right)$ & $15.8(14.9,17.0)$ & $15.9(15.0,17.0)$ & 0.662 \\
\hline $\mathrm{Zn}(\mathrm{mg} / \mathrm{L})$ & $5.54(5.27,5.74)$ & $5.67(5.38,6.23)$ & $0.009^{\star \star}$ \\
\hline $\mathrm{Cu}(\mathrm{mg} / \mathrm{L})$ & $1.27 \pm 0.167$ & $1.26 \pm 0.156$ & 0.825 \\
\hline $\mathrm{Fe}(\mathrm{mg} / \mathrm{L})$ & $\begin{array}{c}428.82(424.83 \\
435.80)\end{array}$ & $\begin{array}{c}434.16(426.67 \\
445.92)\end{array}$ & $0.001^{\star \star}$ \\
\hline $\mathrm{Ca}(\mathrm{mg} / \mathrm{L})$ & $\begin{array}{l}66.72(65.31 \\
\quad 68.16)\end{array}$ & $\begin{array}{c}66.58(64.87 \\
68.55)\end{array}$ & 0.625 \\
\hline $\mathrm{Mg}(\mathrm{mg} / \mathrm{L})$ & $36.38 \pm 3.817$ & $35.88 \pm 3.478$ & 0.361 \\
\hline $\mathrm{Pb}(\mu \mathrm{g} / \mathrm{L})$ & $\begin{array}{l}47.00(44.00 \\
49.00)\end{array}$ & $\begin{array}{l}40.60(32.21 \\
48.90)\end{array}$ & $0.000^{\star \star \star}$ \\
\hline Z score & $0.6(-0.1,1.1)$ & $0.5(-0.3,1.0)$ & 0.243 \\
\hline
\end{tabular}

${ }^{*} p<0.05 ;{ }^{* *} p<0.01 ;{ }^{* * *} p<0.001 ;{ }^{\circ}$ degree 


\section{Multiple Linear Regression Analysis of Bone Mineral Density-Related Factors}

After adjustments were made for the above confounding factors, paternal childbearing age $(\mathrm{p}=0.012)$ was still found to negatively affect the BMD $\mathrm{Z}$ score independently, which means that the higher the paternal age was, the lower the $\mathrm{Z}$ score would be. Grouping $(\mathrm{p}=0.004)$ positively affected the $\mathrm{Z}$ score of BMD, and the effect was greater than that of the father's age. In other words, the $\mathrm{Z}$ score of the ART group was higher than that of the control group (Table 2).

\section{Subgroup Analysis of Bone Mineral Density-Related Factors}

Next, we divided the ART group into different subgroups according to the ART method, infertility factors and embryo transfer cycles to find the source of the difference in BMD between the two groups.

In the ART method subgroup analysis (Table 3) IVF $(p=0.026)$ and ICSI $(p=0.008)$ had a positive impact on the $Z$ score of BMD, and ICSI had a greater impact. This finding indicates that IVF or ICSI technology may affect the $\mathrm{Z}$ score of BMD.

In the infertility factor subgroup analysis (Table 4), PCOS alone was not shown to affect the $\mathrm{Z}$ score of BMD compared with natural conception; however, male infertility $(\mathrm{p}=0.010)$ or male infertility combined with PCOS $(\mathrm{p}=0.026)$ positively affected the $\mathrm{Z}$ score, and the impact of male infertility combined with PCOS was greater. This finding indicates that paternal infertility may affect the BMD of offspring.

In the embryo transfer cycle subgroup analysis (Table 5), compared with natural conception, both stimulation cycle fresh embryo transfer $(p=0.019)$ and natural cycle frozen embryo transfer $(\mathrm{p}=0.006)$ had a positive effect on the bone density $\mathrm{Z}$ score, and natural cycle frozen embryo transfer had a greater impact. This finding indicates that abnormal maternal hormone levels during fresh embryo transfer and frozen embryo technology may affect BMD.

TABLE 2 | Multiple linear regression analysis of bone mineral density group category.

\begin{tabular}{lcccc}
\hline & $\beta$-value & \multicolumn{2}{c}{$95 \%$ CI } & P value \\
\hline Maternal childbearing age & 0.027 & -0.030 & 0.083 & 0.359 \\
Maternal weight & -0.012 & -0.057 & 0.034 & 0.611 \\
Maternal BMl & -0.006 & -0.136 & 0.125 & 0.932 \\
Maternal alcohol consumption & -0.131 & -0.320 & 0.057 & 0.301 \\
Paternal childbearing age & -0.059 & -0.104 & -0.013 & $0.012^{*}$ \\
Paternal smoking & -0.062 & -0.188 & 0.064 & 0.333 \\
Delivery mode: spontaneous delivery & -0.239 & -0.588 & 0.111 & 0.179 \\
Cesarean section(reference) & & & & \\
Zn & -0.177 & -0.477 & 0.124 & 0.247 \\
Fe & 0.001 & -0.004 & 0.006 & 0.692 \\
Pb & -0.010 & -0.022 & 0.003 & 0.123 \\
Group category: ART group & 0.559 & 0.186 & 0.931 & $0.004^{* *}$ \\
NC group (reference) & & & & \\
\hline
\end{tabular}

${ }^{*} p<0.05,{ }^{* *} p<0.01$.
TABLE 3 | Multiple linear regression analysis of bone mineral density- ART methods.

\begin{tabular}{lcccc}
\hline & $\boldsymbol{\beta}$-value & $\mathbf{9 5 \%} \mathbf{C l}$ & P value \\
\hline Maternal childbearing age & 0.027 & -0.030 & 0.084 & 0.350 \\
Maternal weight & -0.014 & -0.060 & 0.032 & 0.547 \\
Maternal BMl & 0.003 & -0.132 & 0.137 & 0.966 \\
Maternal alcohol consumption & -0.126 & -0.316 & 0.065 & 0.194 \\
Paternal childbearing age & -0.059 & -0.105 & -0.013 & $0.012^{\star}$ \\
Paternal smoking & -0.061 & -0.188 & 0.065 & 0.339 \\
Delivery mode: Spontaneous delivery & -0.235 & -0.586 & 0.115 & 0.186 \\
Cesarean section(reference) & & & & \\
Zn & -0.167 & -0.470 & 0.137 & 0.279 \\
Fe & 0.001 & -0.004 & 0.006 & 0.715 \\
Pb & -0.010 & -0.023 & 0.003 & 0.121 \\
ART methods: IVF (48) & 0.494 & 0.059 & 0.929 & $0.026^{\star}$ \\
ICSI (36) & 0.639 & 0.174 & 1.105 & $0.008^{\star *}$ \\
NC (reference) & & & &
\end{tabular}

${ }^{*} p<0.05,{ }^{* *} p<0.01$

TABLE 4 | Multiple linear regression analysis of bone mineral density - Infertility factors.

\begin{tabular}{lcccc}
\hline & $\boldsymbol{\beta}$-value & $\mathbf{9 5 \%} \mathbf{C l}$ & P value \\
\hline Maternal childbearing age & 0.025 & -0.032 & 0.082 & 0.386 \\
Maternal weight & -0.010 & -0.056 & 0.037 & 0.677 \\
Maternal BMl & -0.013 & -0.149 & 0.122 & 0.846 \\
Maternal alcohol consumption & -0.136 & -0.327 & 0.055 & 0.160 \\
Paternal childbearing age & -0.057 & -0.103 & -0.011 & $0.016^{*}$ \\
Paternal smoking & -0.061 & -0.188 & 0.067 & 0.348 \\
Delivery mode: spontaneous delivery & -0.222 & -0.575 & 0.130 & 0.214 \\
Cesarean section (reference) & & & & \\
Zn & -0.178 & -0.480 & 0.124 & 0.246 \\
Fe & 0.001 & -0.004 & 0.006 & 0.678 \\
Pb & -0.010 & -0.023 & 0.003 & 0.117 \\
Infertility factors: PCOS (22) & 0.443 & -0.095 & 0.982 & 0.106 \\
$\quad$ male infertility (52) & 0.554 & 0.132 & 0.976 & $0.010^{*}$ \\
$\quad$ male infertility combined with PCOS (10) & 0.861 & 0.106 & 1.615 & $0.026^{*}$ \\
$\quad$ NC (reference) & & & &
\end{tabular}

${ }^{*} p<0.05$.

TABLE 5 | Multiple linear regression analysis of bone mineral density- embryo transfer cycles.

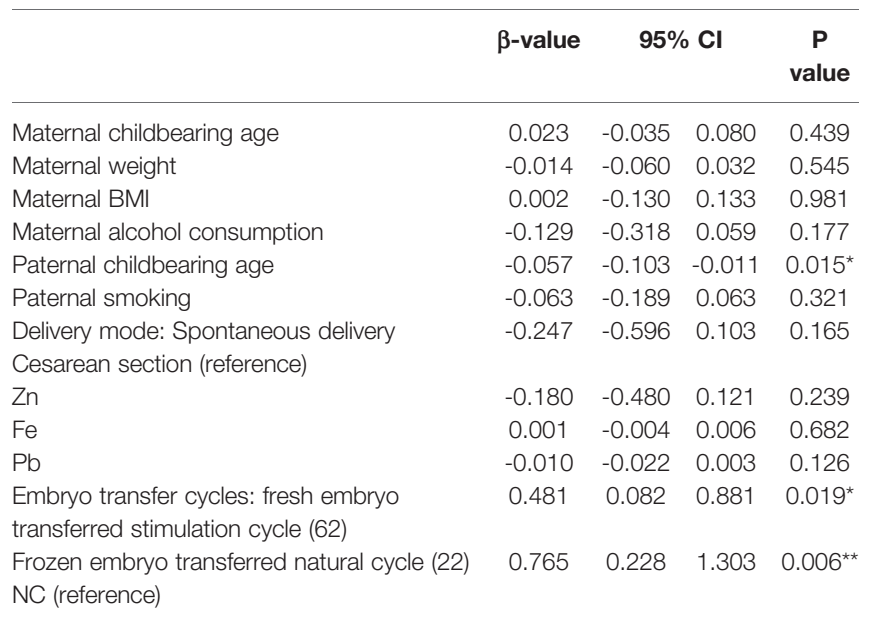

${ }^{*} p<0.05,{ }^{* *} p<0.01$. 


\section{DISCUSSION}

ART has been used to treat infertility for more than 40 years. It has been confirmed that ART is associated with adverse perinatal outcomes, including premature birth, low birth weight, and increased risk of birth defects. A poor ART intrauterine environment and ART gamete manipulation, among other factors, are considered to be possible causes of poor ART pregnancy outcomes $(35,36)$. Therefore, the following question remains: as the child ages, is the growth and development of the ART-conceived offspring the same as that of the NC offspring?

Bone density characterizes bone development. Childhood is a critical period for bone development. Prevention and treatment of childhood bone mineral deficiency is important for reducing childhood rickets and osteoporosis in adulthood. Therefore, it is particularly important to assess the bone density of offspring conceived via ART.

Previous studies focused mostly on the BMD of ARTconceived offspring at birth or within a short period of time after birth. There is no long-term follow-up study on the bone development of ART-conceived offspring at preschool age. Therefore, this study focuses on the BMD of preschool-aged ART-conceived offspring. Whether there is a difference between the ART-conceived children and the NC offspring at the same age and the possible influencing factors were examined.

We found that the BMD Z scores of the offspring of the ART group were generally in the normal range and showed no obvious abnormality. This result is consistent with that of a 2007 study: There was no statistically significant difference between the BMD of the offspring conceived via IVF fresh embryo transfer at 4-10 years old and the NC offspring (12). Another study in 2015 showed that the SOS level measured within 96 hours in ART-conceived preterm infants was lower than that in infants in the NC group (11). The author suggested that this difference may be due to epigenetic changes in imprinted genes or other genes that undergo epigenetic modifications and participate in growth and the bone state. However, the number of participants in the study was relatively small, including only 37 ART-conceived infants (IVF or ICSI, no distinction between fresh embryos or frozen embryos) and $51 \mathrm{NC}$ infants.

Our results revealed that the offspring of the ART group and the NC group had differences in maternal and paternal age, maternal weight, maternal BMI, maternal alcohol consumption, paternal smoking, delivery method, and serum zinc, iron, and lead levels.

The maternal and paternal ages in the ART group were higher than those in the NC group. This finding is consistent with previous studies $(12,37)$. Age is an independent risk factor affecting fertility; the older the age is, the higher the incidence of infertility. Thus, the childbearing age in the ART group was obviously higher than that in the NC group. Interestingly, after adjustments were made for the relevant variables in this study, maternal age no longer showed an independent effect on the $\mathrm{BMD} \mathrm{Z}$ score. Instead, paternal age negatively affected the BMD
$\mathrm{Z}$ score. A paternal childbearing age $>40$ years is associated with an increased risk of spontaneous abortion (38-41), and advanced paternal age is associated with autosomal dominant disorders, such as Alport syndrome, achondroplasia and neurofibromatosis (42-46). There are also cohort studies and population studies showing that advanced paternal age is related to autism spectrum disorders and schizophrenia. A large prospective study of autism in Denmark with 1 million children found that the relative risk associated with a father's age from 40 to 44 years was 1.6 (47), and a cohort study in Israel found that the odds ratio for a father's age from 40 to 49 years was 5.75 (48). A large American study found that for every 10-year increase in paternal age, the relative risk of autism was 1.3 (49). Another study in Israel showed that the relative risk of having offspring with schizophrenia was 2.0 for fathers 45 to 49 years and 3.0 for fathers $>50$ years (50). Similar results have been observed in studies of other ethnic populations, including populations in Denmark, Sweden, and Japan (51-53).

Multifactor analysis with adjustments for relevant factors showed that paternal childbearing age and group category still significantly affected the $\mathrm{Z}$ score of the BMD. The possible reasons are as follows.

First, ART progeny may have subtle changes in the DNA methylation patterns of imprinted genes related to bone development. It has been reported in the literature that there is an increased risk of Beckwith-Wiedemwann syndrome in offspring conceived via ART (54-56). Although there is no description of the bone density of children with BeckwithWiedemwann syndrome, relatives of children with BeckwithWiedemann syndrome have been found to have higher childhood heights $(12,57)$. The phenotypic characteristics of being tall and having normal body weight confirm that the increase in the bone density $\mathrm{Z}$ score of ART-conceived offspring may be a subtle change in the DNA methylation pattern of imprinted genes related to skeletal development.

Second, ART-conceived offspring are exposed to supraphysiological doses of oestrogen in utero. The process of ART ovulation induces a high estrogen environment in the mother's uterus, and estrogen promotes the development of the child's bones. Estrogen can reduce the strain set point of the mechanical regulation system on the bone surface of the endosteum and increase the accumulation of bone in the cortex, causing thickening of the cortex $(58,59)$. In this study, to identify the possible reasons for the higher BMD of the ART offspring, the ART group was divided into different subgroups according to the ART method, infertility factors or embryo transfer cycle. In the ART group (62 cases), the BMD Z score was higher than that in the control group, verifying our hypothesis.

Skeletal development is affected by a variety of confounding factors, including genetics (parental bone development), socioeconomic background, nutritional status, and puberty. In our previous research, we collected data on the height of parents and found that the difference in height between the two groups was not statistically significant. Therefore, when we recruited participants, we chose families located in Nanjing, Jiangsu Province, to reduce the gap between family socioeconomic 
backgrounds and increase follow-up compliance. This study failed to accurately collect data on the eating habits of each participant. When we collected the study data, we collected information regarding the family's dietary preferences in the questionnaire: vegetarian, meat-eaters, balanced diet or special eating habits. The vast majority of families consumed a balanced diet, and the offspring's nutritional status was evaluated during the physical examination. It can be roughly considered that there was no significant difference in nutritional status between the two groups. Both groups of offspring were prepubertal children, thus eliminating the influence of pubertal sex hormones on bone development. We used inclusion and exclusion criteria to reduce selection bias, but there may still be potential uncontrolled confounding factors.

\section{CONCLUSION}

Paternal childbearing age can independently affect the BMD Z score, and the higher the father's age is, the lower the bone mineral density $\mathrm{Z}$ score will be. After adjustments were made for related confounding factors, the BMD Z scores of the ART group and the control group were still significantly different, that is, the bone density $\mathrm{Z}$ score in the ART group was significantly higher than that in the control group. The method of conception, ART indications and embryo transfer cycle all had a positive effect on the $\mathrm{Z}$ score of BMD.

\section{Limitations}

The sample size of the subgroups still needs to be expanded to verify the results. However, additional longer-term, prospective follow-up multicenter studies are required to understand the increased risks among children conceived via ART.

\section{REFERENCES}

1. Chiware TM, Vermeulen N, Blondeel K, Farquharson R, Kiarie J, Lundin K, et al. IVF and Other ART in Low- and Middle-Income Countries: A Systematic Landscape Analysis. Hum Reprod Update (2021) 27:213-28. doi: 10.1093/humupd/dmaa047

2. Szamatowicz M. Assisted Reproductive Technology in Reproductive Medicine - Possibilities and Limitations. Ginekol Pol (2016) 87:820-3. doi: 10.5603/GP.2016.0095

3. Inhorn MC, Patrizio P. Infertility Around the Globe: New Thinking on Gender, Reproductive Technologies and Global Movements in the 21st Century. Hum Reprod Update (2015) 21:411-26. doi: 10.1093/humupd/ dmv016

4. Finnstrom O, Kallen B, Lindam A, Nilsson E, Nygren KG, Olausson PO. Maternal and Child Outcome After In Vitro Fertilization-A Review of 25 Years of Population-Based Data From Sweden. Acta Obstet Gynecol Scand (2011) 90:494-500. doi: 10.1111/j.1600-0412.2011.01088.x

5. Hyrapetian M, Loucaides EM, Sutcliffe AG. Health and Disease in Children Born After Assistive Reproductive Therapies (ART). J Reprod Immunol (2014) 106:21-6. doi: 10.1016/j.jri.2014.08.001

6. Lacamara C, Ortega C, Villa S, Pommer R, Schwarze JE. Are Children Born From Singleton Pregnancies Conceived by ICSI at Increased Risk for Congenital Malformations When Compared to Children Conceived Naturally? A Systematic Review and Meta-Analysis. JBRA Assist Reprod (2017) 21:251-9. doi: 10.5935/1518-0557.20170047

\section{DATA AVAILABILITY STATEMENT}

The raw data supporting the conclusions of this article will be made available by the authors, without undue reservation.

\section{ETHICS STATEMENT}

The studies involving human participants were reviewed and approved by Ethic Committee in First Affiliated Hospital of Nanjing Medical University. Written informed consent to participate in this study was provided by the participants' legal guardian/next of kin.

\section{AUTHOR CONTRIBUTIONS}

XX wrote the draft of the manuscript and performed the data analyses. LC, JW, and XY conducted the health tracking survey and acquired the data. LG and $\mathrm{YZ}$ recruited the participants. FD and YC reviewed and edited the manuscript. JL and YM designed the study. All authors contributed to the article and approved the submitted version.

\section{FUNDING}

This work was funded by the National Key Research and Development Program of China (2016YFC1000204, 2017YFC1001300), the National Nature Science Foundation of China (81730041), and The National Key Research and Clinical Centre of Reproductive Medicine in Jiangsu Province of China (YXZXB2016001).

7. Giorgione V, Parazzini F, Fesslova V, Cipriani S, Candiani M, Inversetti A, et al. Congenital Heart Defects in IVF/ICSI Pregnancy: Systematic Review and Meta-Analysis. Ultrasound Obstet Gynecol (2018) 51:33-42. doi: 10.1002/ uog.18932

8. Zheng D, Nguyen QN, Li R, Dang VQ. Is Intracytoplasmic Sperm Injection the Solution for All in Unexplained Infertility? Semin Reprod Med (2020) 38:36-47. doi: 10.1055/s-0040-1719085

9. Luke B, Brown MB, Wantman E, Forestieri NE, Browne ML, Fisher SC, et al. The Risk of Birth Defects With Conception by ART. Hum Reprod (2021) 36:116-29. doi: 10.1093/humrep/deaa272

10. Qin J, Liu X, Sheng X, Wang H, Gao S. Assisted Reproductive Technology and the Risk of Pregnancy-Related Complications and Adverse Pregnancy Outcomes in Singleton Pregnancies: A Meta-Analysis of Cohort Studies. Fertil Steril (2016) 105:73-85.e1-6. doi: 10.1016/j.fertnstert.2015.09.007

11. Armangil D, Gursoy T, Korkmaz A, Ozyuncu O. Decreased Bone Ultrasound Velocity in Premature Infants Conceived With Assisted Reproduction. Turk J Pediatr (2015) 57:17-25.

12. Miles HL, Hofman PL, Peek J, Harris M, Wilson D, Robinson EM, et al. In Vitro Fertilization Improves Childhood Growth and Metabolism. J Clin Endocrinol Metab (2007) 92:3441-5. doi: 10.1210/jc.2006-2465

13. Yu F, Xia W. The Epidemiology of Osteoporosis, Associated Fragility Fractures, and Management Gap in China. Arch Osteoporos (2019) 14:32. doi: 10.1007/s11657-018-0549-y

14. Henwood MJ, Binkovitz L. Update on Pediatric Bone Health. J Am Osteopath Assoc (2009) 109:5-12. 
15. Bas EK, Bulbul A, Sirzai H, Arslan S, Uslu S, Bas V, et al. The Long-Term Impacts of Preterm Birth and Associated Morbidities on Bone Health in Preschool Children: A Prospective Cross-Sectional Study From Turkey. J Matern Fetal Neonatal Med (2020) 35(4):677-84. doi: 10.1080/14767058. 2020.1730801

16. Nordman H, Voutilainen R, Laitinen T, Antikainen L, Jaaskelainen J. Birth Size, Body Composition, and Adrenal Androgens as Determinants of Bone Mineral Density in Mid-Childhood. Pediatr Res (2018) 83:993-8. doi: 10.1038/pr.2018.12

17. Baradaran Mahdavi S, Daniali SS, Farajzadegan Z, Bahreynian M, Riahi R, Kelishadi R. Association Between Maternal Smoking and Child Bone Mineral Density: A Systematic Review and Meta-Analysis. Environ Sci Pollut Res Int (2020) 27:23538-49. doi: 10.1007/s11356-020-08740-1

18. Sakka SD, Cheung MS. Management of Primary and Secondary Osteoporosis in Children. Ther Adv Musculoskelet Dis (2020) 12:1759720X20969262. doi: $10.1177 / 1759720 X 20969262$

19. Al-Agha AE, Kabli YO, AlBeiruty MG, Milyani AA. Determinants of Bone Mineral Density Through Quantitative Ultrasound Screening of Healthy Children Visiting Ambulatory Paediatric Clinics. Saudi Med J (2019) 40:560-7. doi: 10.15537/smj.2019.6.24234

20. Closa-Monasterolo R, Zaragoza-Jordana M, Ferre N, Luque V, Grote V, Koletzko B, et al. Adequate Calcium Intake During Long Periods Improves Bone Mineral Density in Healthy Children. Data from the Childhood Obesity Project. Clin Nutr (2018) 37:890-6. doi: 10.1016/j.clnu.2017.03.011

21. Yang X, Zhai Y, Zhang J, Chen JY, Liu D, Zhao WH. Combined Effects of Physical Activity and Calcium on Bone Health in Children and Adolescents: A Systematic Review of Randomized Controlled Trials. World J Pediatr (2020) 16:356-65. doi: 10.1007/s12519-019-00330-7

22. Ren Y, Xi X, Hu D, Shang W, Peng S, Fan L, et al. Determinants for Low Bone Mineral Density in Pre-School Children: A Matched Case-Control Study in Wuhan, China. J Pediatr Endocrinol Metab (2019) 32:739-48. doi: 10.1515/ jpem-2018-0554

23. Denova-Gutierrez E, Mendez-Sanchez L, Munoz-Aguirre P, Tucker KL, Clark P. Dietary Patterns, Bone Mineral Density, and Risk of Fractures: A Systematic Review and Meta-Analysis. Nutrients (2018) 10:1922. doi: 10.3390/ nu10121922

24. Rokoff LB, Rifas-Shiman SL, Switkowski KM, Young JG, Rosen CJ, Oken E, et al. Body Composition and Bone Mineral Density in Childhood. Bone (2019) 121:9-15. doi: 10.1016/j.bone.2018.12.009

25. Soininen S, Sidoroff V, Lindi V, Mahonen A, Kroger L, Kroger H, et al. Body Fat Mass, Lean Body Mass and Associated Biomarkers as Determinants of Bone Mineral Density in Children 6-8years of Age - The Physical Activity and Nutrition in Children (PANIC) Study. Bone (2018) 108:106-14. doi: 10.1016/ j.bone.2018.01.003

26. Fintini D, Cianfarani S, Cofini M, Andreoletti A, Ubertini GM, Cappa M, et al. The Bones of Children With Obesity. Front Endocrinol (Lausanne) (2020) 11:200. doi: 10.3389/fendo.2020.00200

27. Kindler JM, Kelly A, Khoury PR, Levitt Katz LE, Urbina EM, Zemel BS. Bone Mass and Density in Youth With Type 2 Diabetes, Obesity, and Healthy Weight. Diabetes Care (2020) 43:2544-52. doi: 10.2337/dc19-2164

28. Lee HS, Rho JG, Kum CD, Lim JS, Hwang JS. Low Bone Mineral Density at Initial Diagnosis in Children and Adolescents With Graves' Disease. J Clin Densitom (2021) 24:275-80. doi: 10.1016/j.jocd.2020.05.006

29. Mantovani A, Gatti D, Zoppini G, Lippi G, Bonora E, Byrne CD, et al. Association Between Nonalcoholic Fatty Liver Disease and Reduced Bone Mineral Density in Children: A Meta-Analysis. Hepatology (2019) 70:812-23. doi: 10.1002/hep.30538

30. Zhao Y, Qin R, Ma X, Qin Z, Yang Z, Hong H, et al. Adiposity Is Not Beneficial to Bone Mineral Density in 0-5 Year Old Chinese Children: The Jiangsu Bone Health Study. Obes Res Clin Pract (2020) 14:39-46. doi: 10.1016/ j.orcp.2019.10.011

31. Ashritha A, Delhi Kumar CG, Sahoo J, Nalini P. Evaluation of Bone Mineral Density in Children With Hemophilia: An Observational Case-Control Study. J Pediatr Hematol Oncol (2019) 41:511-4. doi: 10.1097/MPH. 0000000000001554

32. Fedewa MV, Bentley JL, Higgins S, Kindler JM, Esco MR, MacDonald HV. Celiac Disease and Bone Health in Children and Adolescents: A Systematic
Review and Meta-Analysis. J Clin Densitom (2020) 23:200-11. doi: 10.1016/ j.jocd.2019.02.003

33. Alvarez Zaragoza C, Vasquez Garibay EM, Garcia Contreras AA, Larrosa Haro A, Romero Velarde E, Rea Rosas A, et al. Bone Mineral Density and Nutritional Status in Children With Quadriplegic Cerebral Palsy. Arch Osteoporos (2018) 13:17. doi: 10.1007/s11657-018-0434-8

34. Inaba H, Cao X, Han AQ, Panetta JC, Ness KK, Metzger ML, et al. Bone Mineral Density in Children With Acute Lymphoblastic Leukemia. Cancer (2018) 124:1025-35. doi: 10.1002/cncr.31184

35. Aitken RJ. Age, the Environment and Our Reproductive Future: Bonking Baby Boomers and the Future of Sex. Reproduction (2014) 147:S1-S11. doi: 10.1530/REP-13-0399

36. Agarwal A, Durairajanayagam D, du Plessis SS. Utility of Antioxidants During Assisted Reproductive Techniques: An Evidence Based Review. Reprod Biol Endocrinol (2014) 12:112. doi: 10.1186/1477-7827-12-112

37. Bonduelle M, Wennerholm UB, Loft A, Tarlatzis BC, Peters C, Henriet S, et al. A Multi-Centre Cohort Study of the Physical Health of 5-Year-Old Children Conceived After Intracytoplasmic Sperm Injection, In Vitro Fertilization and Natural Conception. Hum Reprod (2005) 20:413-9. doi: 10.1093/humrep/ deh592

38. Kleinhaus K, Perrin M, Friedlander Y, Paltiel O, Malaspina D, Harlap S. Paternal Age and Spontaneous Abortion. Obstet Gynecol (2006) 108:369-77. doi: 10.1097/01.AOG.0000224606.26514.3a

39. Nguyen BT, Chang EJ, Bendikson KA. Advanced Paternal Age and the Risk of Spontaneous Abortion: An Analysis of the Combined 2011-2013 and 20132015 National Survey of Family Growth. Am J Obstet Gynecol (2019) 221:476 e1-7. doi: 10.1016/j.ajog.2019.05.028

40. Slama R, Bouyer J, Windham G, Fenster L, Werwatz A, Swan SH. Influence of Paternal Age on the Risk of Spontaneous Abortion. Am J Epidemiol (2005) 161:816-23. doi: 10.1093/aje/kwi097

41. Maconochie N, Doyle P, Prior S, Simmons R. Risk Factors for First Trimester Miscarriage-Results From a UK-Population-Based Case-Control Study. BJOG (2007) 114:170-86. doi: 10.1111/j.1471-0528.2006.01193.x

42. Riccardi VM, Dobson CE2nd, Chakraborty R, Bontke C. The Pathophysiology of Neurofibromatosis: IX. Paternal Age as a Factor in the Origin of New Mutations. Am J Med Genet (1984) 18:169-76. doi: 10.1002/ajmg.1320180121

43. Orioli IM, Castilla EE, Scarano G, Mastroiacovo P. Effect of Paternal Age in Achondroplasia, Thanatophoric Dysplasia, and Osteogenesis Imperfecta. Am J Med Genet (1995) 59:209-17. doi: 10.1002/ajmg.1320590218

44. Carothers AD, McAllion SJ, Paterson CR. Risk of Dominant Mutation in Older Fathers: Evidence From Osteogenesis Imperfecta. J Med Genet (1986) 23:227-30. doi: 10.1136/jmg.23.3.227

45. Jadayel D, Fain P, Upadhyaya M, Ponder MA, Huson SM, Carey J, et al. Paternal Origin of New Mutations in Von Recklinghausen Neurofibromatosis. Nature (1990) 343:558-9. doi: 10.1038/343558a0

46. North K. Neurofibromatosis Type 1: Review of the First 200 Patients in an Australian Clinic. J Child Neurol (1993) 8:395-402. doi: 10.1177/ 088307389300800421

47. Lauritsen MB, Pedersen CB, Mortensen PB. Effects of Familial Risk Factors and Place of Birth on the Risk of Autism: A Nationwide Register-Based Study. J Child Psychol Psychiatry (2005) 46:963-71. doi: 10.1111/j.1469-7610.2004.00391.x

48. Reichenberg A, Gross R, Weiser M, Bresnahan M, Silverman J, Harlap S, et al. Advancing Paternal Age and Autism. Arch Gen Psychiatry (2006) 63:1026-32. doi: 10.1001/archpsyc.63.9.1026

49. Croen LA, Najjar DV, Fireman B, Grether JK. Maternal and Paternal Age and Risk of Autism Spectrum Disorders. Arch Pediatr Adolesc Med (2007) 161:334-40. doi: 10.1001/archpedi.161.4.334

50. Malaspina D, Harlap S, Fennig S, Heiman D, Nahon D, Feldman D, et al. Advancing Paternal Age and the Risk of Schizophrenia. Arch Gen Psychiatry (2001) 58:361-7. doi: 10.1001/archpsyc.58.4.361

51. Byrne M, Agerbo E, Ewald H, Eaton WW, Mortensen PB. Parental Age and Risk of Schizophrenia: A Case-Control Study. Arch Gen Psychiatry (2003) 60:673-8. doi: 10.1001/archpsyc.60.7.673

52. Tsuchiya KJ, Takagai S, Kawai M, Matsumoto H, Nakamura K, Minabe Y, et al. Advanced Paternal Age Associated With an Elevated Risk for Schizophrenia in Offspring in a Japanese Population. Schizophr Res (2005) 76:337-42. doi: 10.1016/j.schres.2005.03.004 
53. Zammit S, Allebeck P, Dalman C, Lundberg I, Hemmingson T, Owen MJ, et al. Paternal Age and Risk for Schizophrenia. Br J Psychiatry (2003) 183:4058. doi: 10.1192/bjp.183.5.405

54. Gicquel C, Gaston V, Mandelbaum J, Siffroi JP, Flahault A, Le Bouc Y. In Vitro Fertilization May Increase the Risk of Beckwith-Wiedemann Syndrome Related to the Abnormal Imprinting of the KCN1OT Gene. Am J Hum Genet (2003) 72:1338-41. doi: 10.1086/374824

55. DeBaun MR, Niemitz EL, Feinberg AP. Association of In Vitro Fertilization With Beckwith-Wiedemann Syndrome and Epigenetic Alterations of LIT1 and H19. Am J Hum Genet (2003) 72:156-60. doi: 10.1086/346031

56. Hattori H, Hiura H, Kitamura A, Miyauchi N, Kobayashi N, Takahashi S, et al. Association of Four Imprinting Disorders and ART. Clin Epigenet (2019) 11:21. doi: 10.1186/s13148-019-0623-3

57. Elliott M, Bayly R, Cole T, Temple IK, Maher ER. Clinical Features and Natural History of Beckwith-Wiedemann Syndrome: Presentation of 74 New Cases. Clin Genet (1994) 46:168-74. doi: 10.1111/j.1399-0004.1994. tb04219.x

58. Lanyon LE. Using Functional Loading to Influence Bone Mass and Architecture: Objectives, Mechanisms, and Relationship With Estrogen of the Mechanically Adaptive Process in Bone. Bone (1996) 18:37S-43S. doi: 10.1016/8756-3282(95)00378-9
59. Rodan GA. Mechanical Loading, Estrogen Deficiency, and the Coupling of Bone Formation to Bone Resorption. J Bone Miner Res (1991) 6:527-30. doi: 10.1002/jbmr.5650060602

Conflict of Interest: The authors declare that the research was conducted in the absence of any commercial or financial relationships that could be construed as a potential conflict of interest.

Publisher's Note: All claims expressed in this article are solely those of the authors and do not necessarily represent those of their affiliated organizations, or those of the publisher, the editors and the reviewers. Any product that may be evaluated in this article, or claim that may be made by its manufacturer, is not guaranteed or endorsed by the publisher.

Copyright () 2022 Xia, Chen, Wang, Yu, Gao, Zhang, Diao, Cui, Liu and Meng. This is an open-access article distributed under the terms of the Creative Commons Attribution License (CC BY). The use, distribution or reproduction in other forums is permitted, provided the original author(s) and the copyright owner(s) are credited and that the original publication in this journal is cited, in accordance with accepted academic practice. No use, distribution or reproduction is permitted which does not comply with these terms. 